\title{
Computer-based vs. Paper-based Writing Tests: A Comparative Study of Test Taking Strategies
}

\author{
Masoud Zoghi \\ Dept. of ELT, Ahar Branch, Islamic Azad University, Ahar, Iran \\ E-mail:m-zoghi@iau-ahar.ac.ir \\ Elnaz Reshadi (Corresponding author) \\ Dept. of ELT, Ahar Branch, Islamic Azad University, Ahar, Iran \\ E-mail: e.reshadi@iau-ahar.ac.ir
}

Received: March 19, 2013 Accepted: April 19, $2013 \quad$ Published: April 21, 2013

doi:10.5296/ijele.v1i3.3559 URL: http://dx.doi.org/10.5296/ijele.v1i3.3559

\begin{abstract}
This study was an attempt to compare the use of test taking strategies in computer-based writing test (CBWT) and paper-based writing test (PBWT) in an Iranian context. To that end, the researchers selected 30 test takers from Payam-Nour University of Shabestar and assigned them into two groups i.e. the CBWT group $(n=15)$ and PBWT group $(n=15)$. The participants in both groups took a writing test and produced verbal reports. Collecting the data, the researchers coded the verbal reports based on Mu's(2005) taxonomy of ESL writing strategies. The result showed that test takers in both groups were similar in the use of top four sub-strategies (i.e. organization, planning, sense of readers and revising). Also, it was known that both groups did not draw on two types of social/affective strategies (resourcing and summarizing) and on one kind of cognitive strategies (summarizing). This study contributes to the language testing field in several ways: (a) by providing insight into individual differences among test takers, and (b) by revealing the importance of test taker differences in different test administration modes. Overall, the findings may be beneficial not only to test-takers but also to test developers and administrators in particular. The conclusions and recommendations for future studies are discussed accordingly.
\end{abstract}

Keywords: CBWT, PBWT, Test taking strategies 


\section{Introduction}

Language testing (LT) research can be considered as a subcomponent of second language acquisition (SLA) research. Bachman and Cohen (1998) hold the view that like SLA research, LT research focuses on sources of variation. The first source of variation, as mentioned by Bachman and Cohen (1998), refers to the individual differences in the language abilities that are acquired or measured. Individual differences in the strategies and other processes that individuals employ in language use, as well as in language test tasks and SLA elicitation can be considered as the second source of variation. Additionally, variation in the tasks and context and their effects on language use, as well as on the performance in language test tasks and SLA elicitation tasks are assumed by Bachman and Cohen (1998) as the last source of variation.

Concerning the second source of variation, it should be noted that individual differences in learner strategies did not become significant in LT research until 1970s when researchers felt a need to study the strategies test takers use in order to obtain correct answers to a class of items. According to Cohen (2006), researchers, in fact, became interested in what the test takers were actually doing to produce answers to questions. It is believed that test taking strategies are subservient to language use strategies (Cohen, 1998). Thus, in order to explain test taking strategies, one needs to have an understanding of second language learner strategies.

Cohen (1998) specifies five major purposes which are fulfilled by language learner strategies. The purposes are to enhance learning, to perform specified tasks, to solve specific problems, to make learning easier, faster, and more enjoyable, to compensate for a deficit in learning. It is declared by Coombe et al (2007) that "effective test taking strategies are synonymous with effective learning strategies"(p.133). Based on this statement the researchers assumed that Cohen's (1998) purposes can be related to LT strategies.

Research in the realm of test-taking strategy is a unified and classified process which mainly focuses on a number of varying themes. Cohen (2006) has summarized the themes in test-taking strategy research. He believes that (a) conceptual frameworks for classifying strategies, (b) L1 and L2 related strategies, (c) proficiency level and test-taking strategies, (d) strategies as functions of testing method, and finally (e) appropriateness of the research methods are among the most important themes in test-taking strategy research.

Brown (2004) categorizes writing performance into four general types: imitative, intensive, responsive, and extensive. All the four categories of writing performance can be carried out either with a pen and paper or on the computer. Whereas the former is paper-based administration, the latter can be considered as computer-based administration of writing test. Mousavi (1999) defines the computer-administered test as a test that is bound to the computer in terms of preparation, administration and scoring. In other words, he describes it as a test that is prepared or adapted so that it can be administered and scored by a computer.

\subsection{Review of Literature}

There have been some studies that have focused on the relationship between test taking 
strategies and test performance. For instance, Song (2005) examined the nature of language strategies reported by test takers of the Michigan English Language Assessment Battery. He further investigated test performance and test taker's reported strategy use. The findings showed that test takers in this study used six dimensions of cognitive strategies: repeating/confirming information strategies, writing strategies, practicing strategies, generating strategies, applying rules strategies, and linking with prior knowledge strategies. They also used three types of metacognitive strategies, i.e. monitoring, evaluating, and assessing. Regarding strategy types and test performance, Song' (2005) study revealed both negative and positive effects.

Moreover, Stathopoulou and Nikaki (2009) studied the test-taking strategies used by Greek users of English when performing the activities of the Greek State Language Exams, which is known as Kratiko Pistopiitiko Glossomathias. The list of the reading test-taking strategies, which was presented in the results, included a variety of cognitive, metacognitive, support and test-wiseness test-taking strategies.

In a recent study, Zhang et al (2011) investigated the relationship between English test taking strategy use and student's test performance. They classified the findings of their research into six groups: (a) the results showed that the students had a medium use of English test-taking strategies; (b)whereas metacognitive strategies were the most-often-used individual strategies, memory strategies were the-least-often-used ones; (c)test-taking strategies and overall strategy use were positively correlated with one another; (d) students' test performance was significantly correlated with compensation and social strategies; (e) most of the metacognitive strategies were positively correlated with test performance; and (f) a significant difference was seen in the use of memory strategies among students in different study years.

Lee (2011) compared the strategies used by Chinese speaking students when confronted with familiar versus unfamiliar topics in a reading test of multiple-choice format. Lee's study showed that the strategies that the participants employed while taking reading multiple-choice tests were similar regardless of topic familiarity.

Sapsirin et al (2009) investigated the strategies used by examinees when performing a computer based speaking test. The data were collected from nine university students through a retrospective interview. The results showed that the examinees used several strategies, ranging from goal setting, assessment, planning to communication strategies. These strategies seemed to be associated with the constructs the computer-based speaking test aimed to measure.

Concerning computer-based and paper-based testing, Al-Amri (2008) explored their comparability in an L2 reading context. In fact, he examined the impact of test takers' characteristics, i.e., computer familiarity, computer attitude, testing mode preference and test taking strategies, on students' performance on computer-based tests, and in comparison with paper-based tests. Al-Amri's (2008) study reported on the results of the quantitative instruments of the study. The results indicated a significant difference between the mean scores on both modes. None of the factors examined by Al-Amri (2008) had an influence on 
students' performance when doing the computer-based tests.

The literature reviewed above shows a significant relationship between test performance and test taking strategy use. It also reveals that some strategies are more prominent in some testing situations than others. Meanwhile, computer-based testing situations required the use of specific test-taking strategy types. However, there is a gap in studies conducted in the Iranian EFL context through which test-taking strategies used by test takers in computer-based and paper-based writing tests are compared. While arguing that the type of test administration may affect test taking strategies, the researchers attempted to investigate the type of writing strategies employed both in paper-based writing tests and in computer-based writing tests.

The main motive for this study was that computer-based assessment is becoming a widely accepted practice in the new millennium. The administration of some well-known and worldwide proficiency tests such as TOEFL and PET is a major indicator of this fact. Hence, it seems reasonable to conduct a comparative study with a focus on the type of strategies used in both computer-based writing tests and paper-based writing tests. In this way, findings may help us gain further insight into test-taking strategies and test types.

\subsection{Research Questions and Hypothesis}

Considering the purpose of the study, the following research question was posed:

- $\quad$ Do test takers use different test taking strategies while taking computer-based as opposed to paper-based writing test?

Based on the research question, the researchers hypothesized that test takers use different test taking strategies while taking computer-based as opposed to paper-based writing test.

\section{Method}

\subsection{Participants}

The participants of this study were 30 university students majoring English Language Translation from Payam-Nour University of Shabestar. They were assigned to two groups based on the type of test they were supposed to take: Paper-Based Writing Test (PBWT) and Computer-Based Writing Test (CBWT). In the PBWT group, there were 15 test takers with an age range of 19-32 (mean=23.5 years old). The participants in the CBWT group consisted of 15 test takers who ranged in age from $21-30$ (mean=24.5 years old). The initial homogeneity of the groups was examined using structure and written expression section of TOEFL (2003). The data from TOEFL test was analyzed using independent samples $t$-test. The results showed that there was no significant difference between the groups, $t(28)=-1.617, p=0.50$. As the participants in both groups were all mature, they seemed to be suitable for this study because they were expected to provide insightful information on what mental processes have been selected while taking PBWT and CBWT.

\subsection{Instruments}

In this study a number of instruments were employed. The first instrument, TOEFL (2003), 
was used to measure the initial homogeneity of both PBWT and CBWT groups. For this reason, the researchers used a 40-item test of structure and written expression of TOEFL (2003).

We also used one part of the writing section of Preliminary English Test (PET, 2004) to examine the test takers' writing performance. The important reason for using PET was that this test can be taken through paper as well as via computer. Besides, as the main objective of this study was to investigate the types of test-taking strategies used while taking computer-based as opposed to paper-based writing test and not estimating test-takers writing performance, it was valuable to free their mind from the extra challenges that a writing test can bring to the context. PET writing test involves three separate sections. The first section consists of five complete sentences with other five incomplete sentences under them. It is the task of test takers to finish the incomplete sentences so that they can have the same meaning as the sentences above them. In the second section of this test the candidates are supposed to write a 35-45 words letter. The last part of the writing section of PET was of great concern to this study. The researchers used this part of PET writing test to provide a proper context for participants to use their test-taking strategies. The researchers used the third part of the writing section of PET to avoid any potential between- task differences which may result in distinct strategy use.

Moreover, this study made use of verbal reports. Mousavi (1999) explained three main techniques for eliciting verbal reports: thinking aloud, introspection and retrospection. We employed the retrospection verbal report which, as mentioned by Mousavi (1999, p.446), "requires the subjects to infer their own mental processes or strategies from their memory of the particular mental event under observation". The main reason for using verbal reports was to elicit the possible test taking strategy types used by the test takers immediately after taking PBWT and CBWT. There is always a concern of the quality of retrospective verbal reports. The researchers used some of Dornyei's (2007) recommendations for improving the quality of retrospective verbal reports in this study. In fact, the participants of this study had prior training on how to produce their mental processes after completing the writing task. The researchers used Johnston and Afflerbach's (1983) training technique which is called pre-study introspection to teach the participants in advance of data collection procedure to think about the processes they use while they are writing. Actually, the researchers of this study asked the participants to think about the processes they are undertaking as they are writing.

The second technique for improving the quality of the verbal reports of this study was that the participants were supposed to produce verbal reports in their official language which is Persian in Iran. Thirdly, the researchers overemphasized the availability of short time interval between writing test and verbal report production.

The last instrument used in this study was a criterion list of test taking strategies. We used Mu's(2005) unified taxonomy of ESL writing strategies as a criterion for analyzing the verbal reports. $\mathrm{Mu}$ (2005) believes that to some extend this taxonomy looks more explicit and accessible than the classifications proposed by others working in the field of writing 
strategies (e.g. Arndt, 1987; Wenden, 1991; Victori, 1995; Riazi, 1997; \&Sasaki, 2000, all cited in $\mathrm{Mu}$ 2005). The five major components of this taxonomy are rhetorical strategies, metcognitive strategies, cognitive strategies, communicative strategies and social/affective strategies. A summary of the taxonomy of ESL writing strategies together with sub-strategies and speculations is provided in Table 1.

Table 1. The Taxonomy of ESL Writing Strategies (Adapted from Mu, 2005)

\begin{tabular}{|c|c|c|}
\hline Writing strategies & Sub-strategies & Speculation \\
\hline Rhetorical strategies & $\begin{array}{l}\text { Organization } \\
\text { Use of L1 } \\
\text { Formatting/Modelling } \\
\text { Comparing }\end{array}$ & $\begin{array}{l}\text { Beginning/development/ending } \\
\text { Translate generated idea into } \\
\text { ESL } \\
\text { Genre consideration } \\
\begin{array}{l}\text { Different } \\
\text { conventions }\end{array}\end{array}$ \\
\hline Meta-cognitive strategies & $\begin{array}{l}\text { Planning } \\
\text { Monitoring } \\
\text { Evaluating }\end{array}$ & $\begin{array}{l}\text { Finding focus } \\
\text { Checking and identifying } \\
\text { problems } \\
\begin{array}{l}\text { Reconsidering written text, } \\
\text { goals }\end{array}\end{array}$ \\
\hline Cognitive strategies & $\begin{array}{l}\text { Generating ideas } \\
\text { Revising } \\
\text { Elaborating } \\
\text { Clarification } \\
\text { Retrieval } \\
\text { Rehearsing } \\
\text { Summarizing }\end{array}$ & $\begin{array}{l}\text { Repeating, lead-in, } \\
\text { inferencing, etc. } \\
\text { Making changes in plan, } \\
\text { written text } \\
\text { Extending the contents of } \\
\text { writing } \\
\text { Disposing of confusions } \\
\text { Getting information from } \\
\text { memory } \\
\text { Trying out ideas or language } \\
\text { Synthesising what has read }\end{array}$ \\
\hline Communicative strategies & $\begin{array}{l}\text { Avoidance } \\
\text { Reduction } \\
\text { Sense of readers }\end{array}$ & $\begin{array}{l}\text { Avoiding some problem } \\
\text { Giving up some difficulties } \\
\text { Anticipating readers' response }\end{array}$ \\
\hline Social/affective strategies & $\begin{array}{l}\text { Resourcing } \\
\text { Getting feedback } \\
\text { Assigning goals } \\
\text { Rest/deferral }\end{array}$ & $\begin{array}{l}\text { Referring to libraries, } \\
\text { dictionaries } \\
\text { Getting support from } \\
\text { professor, peers } \\
\text { Dissolve the load of the task } \\
\text { Reducing anxiety }\end{array}$ \\
\hline
\end{tabular}




\subsection{Procedure}

As an initial step, we obtained verbal permission from the research site to conduct the study. Then, the structure and written expression section of TOEFL (2003) was administered to ensure the homogeneity of the participants in terms of proficiency in both PBWT and CBWT groups. After that, a separate one-hour session was allocated to the administration of PBWT and CPWT. The writing test which was used to elicit test takers' test-taking strategies was PET (2004). The participants in the CBWT group took the writing test in a computer lab. In fact, they first read the instruction on the computer and immediately afterwards took their writing test by typing on the computer. Immediately after finishing the writing test, the participants in this group produced a written verbal report of the processes and procedures they opted for, before, during and after the completion of the CBWT. The same was performed by the PBWT group except for the fact that the participants were in a separate class and used paper and pen to take the writing test. The participants in the CBWT and PBWT groups were asked to write down what came to their thoughts after taking the test. Depending on the learner's preferences, the verbal report lasted from 20 to 40 minutes.

After completing the data collection procedure, the researchers adapted Mu's (2005) taxonomy of ESL writing strategies and used it as a criterion for coding the strategy types used by the participants in both groups. That is, we examined the mean of the CBWT strategy types vs. the PBWT strategy types.

\section{Data Analysis}

As mentioned earlier, in order to obtain useful information from the verbal reports, the researchers used Mu's (2005) taxonomy of ESL writing strategies as a criterion. After reading the verbal reports by two coders, a number of sentences were coded as the specified strategies in Mu's (2005) taxonomy. The reason for the data to be coded by two coders was to assure the consistency of the coding procedure. The researchers further analyzed the data in terms of the mean of the use of CBWT and PBWT strategies.

First of all, we estimated the consistency of the results of the coders. Actually, from the 15 verbal reports produced by the test takers of the PBWT group, a total of 210 sentences were selected. In fact, the written expressions of the participants of this group consisted of only 210 sentences; however, the other expressions were not complete sentences and some of these expressions were left incomplete. Moreover, only 183 sentences were assumed to be used as strategy types. Thus, 87.14 percent of the sentences were considered as strategies by the two coders. Meanwhile, the coder's agreement on coding was 165 sentences $(60.44 \%)$ and the disagreement was 18 sentences (39.76\%). In other words, only 165 sentences were coded as similar strategy types by the two coders and 18 sentences could not be interpreted as same strategies. Thus, 165 sentences were used as the useful data for analyzing the strategy types used by the test takers of the PBWT group.

The verbal reports of the CBWT group resulted in 198 sentences, from which $164(82.83 \%)$ were considered as strategy types. Although the two coders agreed that $153(93.29 \%)$ sentences were strategies, $11(6.71 \%)$ sentences have not been agreed upon as test taking 
strategy types by the two coders.

Subsequently, to analyze the verbal reports, we drew on the sub-strategies of five writing strategy categories suggested by $\mathrm{Mu}$ (2005). The mean of strategies was studied thoroughly for each broad strategy type (Table 2).

Table 2. Mean of Test-taking Strategies Used by Test-takers of CBWT and PBWT

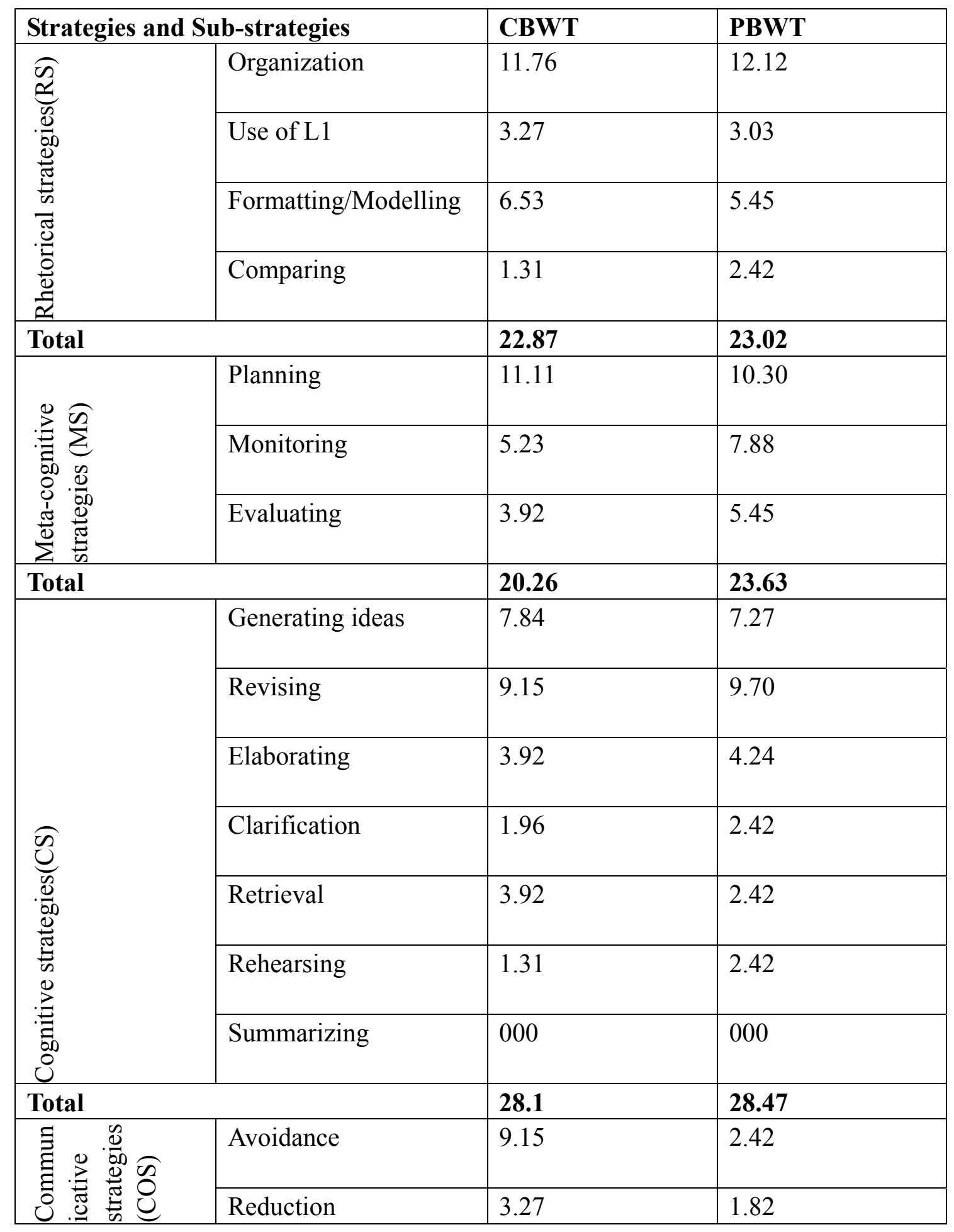




\begin{tabular}{|c|c|c|c|}
\hline & Sense of readers & 9.80 & 10.30 \\
\hline \multicolumn{2}{|l|}{ Total } & 22.22 & 14.54 \\
\hline \multirow{4}{*}{ 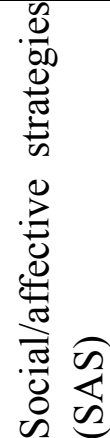 } & Resourcing & 000 & 000 \\
\hline & Getting feedback & 000 & 000 \\
\hline & Assigning goals & 5.23 & 6.67 \\
\hline & Rest/deferral & 1.31 & 3.64 \\
\hline \multicolumn{2}{|l|}{ Total } & 6.54 & 10.31 \\
\hline
\end{tabular}

The first strategy type is referred to as rhetorical strategies. According to $\mathrm{Mu}$ (2005), rhetorical strategies are the ones that writers use to organize and to present their ideas in writing conventions so that they are acceptable to native speakers of English. The mean of the use of rhetorical strategies in the CBWT and PBWT groups are 22.87 and 23.02, respectively. Also, Table 2 illustrates the results of metacognitive strategies for the two groups. As it is presented in this table, whereas the test takers of CBWT use a mean number of 20.26 for metacognitive strategies, the participants in the PBWT group use a mean number of 23.63 for metacognitive strategies

In the case of cognitive strategies, the participants in both groups possess the highest mean; that is, a mean number of 28.10 cognitive strategies were used by CBWT group and a mean number of 28.47 cognitive strategies were used by the PBWT group. Moreover, this table indicates a mean number of 22.22 and 14.54 for the sub-strategies of the broad communicative strategy for the participants in CBWT and PBWT groups, respectively. In contrast to the cognitive strategies which reported the highest values, social/affective strategies possessed the lowest values of strategies in both groups. In other words, the participants of CBWT and PBWT used 6.54 and 10.31 social affective strategies, respectively.

In addition, to conduct the hypothesis testing and to estimate the significance of the differences of the two groups in terms of the use of five general types of writing strategies, the researchers used Mann-Whitney $U$ test. The results of this non-parametric test are presented in Table 3. The results show a p-value of $0.602(p$-value $=0.602>0.05)$ which indicates that CPWT group and PBWT groups are not different in terms of the use of test-taking strategies. 
Table 3. Mann-Whitney U test for Estimating the Differences of CPWT and PBWT Groups in use of Test-taking Strategies

\begin{tabular}{|l|l|}
\hline & $\begin{array}{l}\text { Test-taking } \\
\text { strategy use }\end{array}$ \\
\hline Mann-Whitney U & 10.000 \\
Wilcoxon W & 25.000 \\
Z & -.522 \\
Asymp. Sig. (2-tailed) & .602 \\
Exact Sig. [2*(1-tailed & $.690^{\mathrm{a}}$ \\
Sig.)] & \\
\hline
\end{tabular}

Besides, the ranking of test-taking strategies used by test-takers of CBWT and PBWT are presented in Table 4. The results indicate that top four strategies used by the participants of CBWT and PBWT are the same. That is, the test takers of the two groups were similar in using four most frequent strategy types (i.e., organization, planning, sense of readers and revising). Moreover, the two groups were akin in terms of the least frequent strategies (i.e., clarification, rehearsing and comparing). Additionally, the results reported in this table show that the participants did not use reasoning, getting feedback and summarizing strategies at all.

Table 4. Ranking of Test-taking Strategies Used by Test-takers of CBWT and PBWT

\begin{tabular}{|l|l|l|l|l|}
\hline \multirow{2}{*}{ Rank } & CBWT & \multicolumn{2}{l|}{ PBWT } \\
\cline { 2 - 5 } & Mean & Strategies & Mean & Strategies \\
\hline 1 & 11.76 & Organization (RS) & 12.12 & Organization(RS) \\
\hline 2 & 11.11 & Planning (MS) & 10.30 & Planning (MS) \\
\hline 3 & 9.80 & Sense of readers (COS) & 10.30 & Sense of readers (COS) \\
\hline 4 & 9.15 & Revising (CS) & 9.70 & Revising (CS) \\
\hline 5 & 9.15 & Avoidance (COS) & 7.88 & Monitoring (MS) \\
\hline 6 & 7.84 & Generating ideas (CS) & 7.27 & Generating ideas (CS) \\
\hline 7 & 6.53 & Formatting/modeling(RS) & 6.67 & Assigning goals (SAS) \\
\hline 8 & 5.23 & Monitoring (MS) & 5.45 & Evaluating (MS) \\
\hline 9 & 5.23 & Assigning goals (SAS) & 5.45 & Formatting/modeling(RS) \\
\hline 10 & 3.92 & Retrieval (CS) & 3.64 & Rest/deferral (SAS) \\
\hline 11 & 3.92 & Elaborating (CS) & 3.03 & Use of L1(RS) \\
\hline 12 & 3.92 & Evaluating (MS) & 4.24 & Elaborating (CS) \\
\hline 13 & 3.27 & Use of L1(RS) & 2.42 & Avoidance (COS) \\
\hline 14 & 3.27 & Reduction (COS) & 2.42 & Retrieval (CS) \\
\hline 15 & 1.96 & Clarification (CS) & 2.42 & Clarification (CS) \\
\hline 16 & 1.31 & Rehearsing (CS) & 2.42 & Rehearsing (CS) \\
\hline 17 & 1.31 & Comparing (RS) & 2.42 & Comparing (RS) \\
\hline 18 & 1.31 & Rest/deferral (SAS) & 1.82 & Reduction (COS) \\
\hline 19 & 000 & Resourcing (SAS) & 000 & Resourcing (SAS) \\
\hline
\end{tabular}




\begin{tabular}{|l|l|l|l|l|}
\hline 20 & 000 & Getting feedback (SAS) & 000 & Getting feedback (SAS) \\
\hline 21 & 000 & Summarizing(CS) & 000 & Summarizing(CS) \\
\hline
\end{tabular}

$\mathrm{RS}=$ Rhetorical strategies

MS= Metacognitive strategies

$\mathrm{CS}=$ Cognitive strategies

$\mathrm{COS}=$ Communicative strategies

$\mathrm{SAS}=\mathrm{Social} /$ affective strategies

\section{Discussion}

The study aimed to compare test-takers' preferences in test taking strategies in the CBWT and PBWT settings. The results showed both similarities and differences in participants' test taking strategies. Both of the groups showed similarities in the use of the most and least frequent sub-strategies in this research. That is, the two groups equally made use of organization (RS), planning (MS), sense of readers (COS), and revising (CS) as the most frequent strategy types, and of rehearsing (CS) as the least frequent strategy type. The two groups comparably did not draw on resourcing (SAS), getting feedback (SAS), and summarizing (CS) strategies. However, the findings revealed some distinctions in the frequency of test taking strategy use by the participants of the CBWT and PBWT groups. The differences were noted in such strategies as avoidance (COS), generating ideas (CS), formatting/modeling (RS), monitoring (MS), assigning goals (SAS), retrieval (CS), elaborating (CS), evaluating (MS), use of L1(RS), reduction (COS), clarification (CS), comparing (RS), and rest/deferral (SAS). Generally, the results of Mann Whitney U test showed that the two test administration formats can bring about distinct strategy use.

This study's findings can be compared with the findings of a study conducted by Zhang et al (2011), who examined English test-taking strategy use and its effect on students' test performance at the tertiary level. They administrated an 83-item survey to 526 students in three different study years at a university in Beijing. One of the findings that the study reported was that the most frequently used strategies were compensation strategies, followed by affective, metacognitive, social strategies, cognitive and memory strategies. However, the present study did not reveal such an order. It is evident from the results that the sub-strategies were ranked randomly in the present study. In other words the four most frequent sub-strategies in both groups were related to four distinct categories of strategies; that is, organization as a rhetorical strategy, planning as metacognitive strategy, sense of readers as communicative strategy and revising as a cognitive strategy.

Furthermore, Song (2005) studied language learner strategy use and English proficiency on the Michigan English assessment battery. His study classified test takers' perception of cognitive strategy use into six dimensions: repeating/ conforming information strategy, writing strategies, practicing strategies, generating strategies, applying rules strategies, and linking with prior knowledge strategies. Also, in Michigan English assessment battery, test takers' perception of metacognitive strategies fall into three dimensions: evaluating, assessing 
and monitoring. The strategies presented in Song's (2005) cover a broad context of language use; the present study is similar to Song's (2005) investigation, in that some sub-strategies of the general cognitive and metacognitive strategy type are available in the findings of the present study.

In addition, the findings of this research can be compared with the results of researches that studied computer-based vs. paper-based tests in relation to other test taker characteristics. For instance, Lukin et al (1985) examined the similarities and differences of computer-based assessment and paper-based assessment in relation to personality features. Their results revealed no significant difference in the two testing modes. Our study is akin to this in that both computer-based and paper-based tests reported similarities in the use of strategy types. Moreover, in a rather similar study, Fox and Schwartz (2002) used personality questionnaire to compare computer-based tests and paper-based tests. Similarly, the results of Fox and Schwartz's (2002) study report similarities in the two testing modes.

This study can act as a complement to Al-Amri's (2008) study which provided no clear picture on the relationship of the test taking strategies used by test takers and the two testing modes, i.e. computer-based and paper-based. In fact, he investigated the impact of test takers' characteristics, i.e., computer familiarity, computer attitude, testing mode preference and test taking strategies, on students' performance on computer-based tests, and in comparison with paper-based tests. However, the point is that, he didn't offer a clear picture about the use of test taking- strategies in paper-based and computer-based testing modes. Hence, the present study may complete Al'Amri's (2008) research

\section{Conclusion}

This study compared the use of test taking strategies among the participants who undertook CBWT vs. PBWT. In fact, it aimed at exploring test-takers' preferences in choosing specific test taking strategies while taking writing tests which were administered using computer for one group and paper for another group. The researchers found that the two groups were neither totally similar nor distinct in the use of test taking strategies.

The findings may be beneficial to learners since they provide them with insightful information on the mental processes and individual strategies while taking computer-based and paper-based tests. In particular, the findings are helpful to test developers and administrators as well. Presumably, test developers and administrators will be aware of the different processes that test takers need to undertake in test completion. Based on the predetermined processes, test developers and administrators can modify the elements of the test.

By looking at the available literature, it seems that studies in the field of CBWT in the EFL context of Iran are not enough. Although, computer-based assessment is being a widely accepted phenomenon in the world, in Iran little attention is given to this area. Thus, further research is required in the area of CBWT and test taking strategies. The studies, needless to say, should emphasize the specific elements of CBWT. 


\section{Acknowledgement}

We would like to thank Payam-Nour University of Shabestar for their assistance in collecting the data for the present study. We also wish to thank Payam-Nour University of Shabestar English Language Students for taking part in this project.

\section{References}

Al-Amri, S. (2008). Computer-based testing vs. paper-based testing: a comprehensive approach to examining the comparability of testing modes. Essex Graduate Student Papers in Language \& Linguistics, 10, 22-44.

Bachman, L. F., \& Cohen, A. D. (1998). Inferences between Second Language Acquisition and Language testing research. Cambridge: Cambridge University Press.

Brown, H. D. (2004). Language assessment principles and classroom practices. New York: Longman.

Cohen, A. D. (1998). Strategies and Processes in Test taking and SLA. In L.F. Bachman and A. D. Cohen (Eds.), Inferences between Second Language Acquisition and Language testing research. pp. 90-111.

Cohen, A. D. (2006). The coming of Age for Research on Test-Taking Strategies. In J. Fox, M. Wesche, D. Bayliss, L. Cheng, C. E. Turner, \& C. Doe (Eds.), Language Testing Reconsideration. pp. 89-111.

Coombe, C., Folse, K., \& Hubley, N. (2007). A practical guide to assessing English language learners. Michigan: The University of Michigan Press.

Dornyei, Z. (2007). Research methods in applied linguistics. Oxford: Oxford University Press.

Fox, S., \& Schwartz, D. (2002). Social desirability and controllability in computerized and paperand- pencil personality questionnaires. Computers in Human Behavior, 18(4), 389-410.

Lee, J. Y. (2011). Second language reading topic familiarity and test score: test-taking strategies for multiple-choice comprehension questions dissertation, University of Iowa, 2011. Retrieved from http://ir.uiowa.edu/etd/2737

Lukin, M. E., Dowed, T., Plake, B. C., \& Kraft, R. G. (1985). Comparing computerized versus traditional psychological assessment. Computers in Human Behavior, 1(1), 49-58.

Mousavi, A. (1999). A dictionary of language testing. Teharn: Rahnama publication.

$\mathrm{Mu}, \mathrm{C}$. (2005). A Taxonomy of ESL Writing Strategies. Proceedings Redesigning Pedagogy: Research, Policy, Practice Singapore, 1-10

Sapsirin, S., Parapphal, K., \& Bachman, L. F. (2009). Strategis used in taking a computer-based speaking test: a retrospective verbal protocol study. MANUSYA: Journal of Humanities Regular, 12(1), 2009. 
Song, X. (2005). Language learner strategy use and English proficiency on the Michigan English Language Assessment Battery. Spaan Fellow Working Papers in Second or Foreign Language Assessment, 3, 1-26.

Stathopoulou, M., \& Nikaki, D. (2009). Test-taking strategies in the KPG reading test: instrument construction and investigation results. $J A L, 25,129-148$.

Zhang, W., Liu, M., Zhao, S., \& Xie, Q. (2011). English test-taking strategy use and students' test performance. Asian EFL Journal, 13(2), 133-168.

\section{Copyright Disclaimer}

Copyright reserved by the author(s).

This article is an open-access article distributed under the terms and conditions of the Creative Commons Attribution license (http://creativecommons.org/licenses/by/3.0/). 